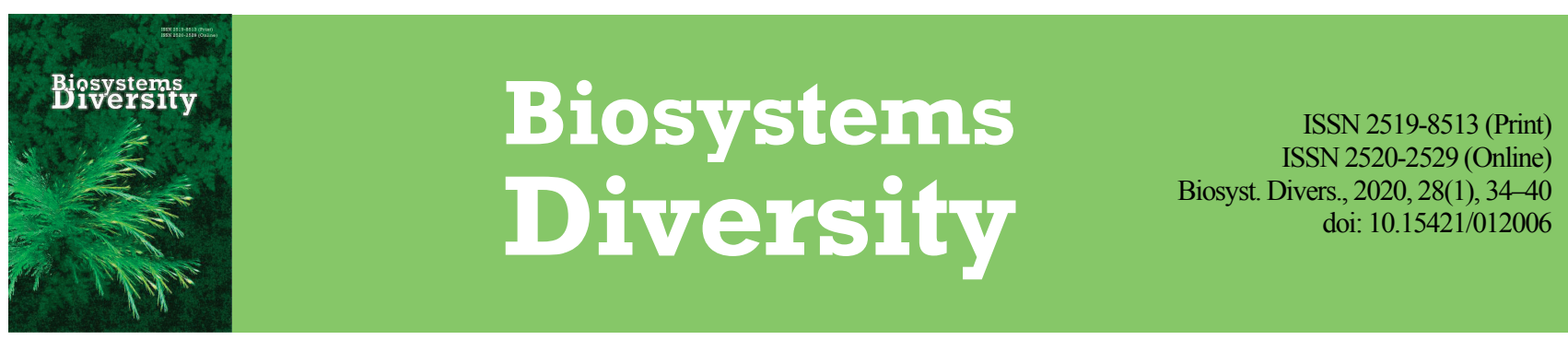

\title{
Temporal dynamic of the phylogenetic diversity of the bird community of agricultural lands in Ukrainian steppe drylands
}

\author{
A. I. Koshelev*, O. Y. Pakhomov**, O. M. Kunakh**, V. A. Koshelev*, M. P. Fedushko* \\ *Bogdan Khmelnitsky Melitopol State Pedagogical University, Melitopol, Ukraine \\ **Oles Honchar Dnipro National University, Dnipro, Ukraine
}

Article info

Received 27.01.2020

Received in revised form

21.02.2020

Accepted 23.02.2020

Bogdan Khmelnitsk

Melitopol State

Pedagogical University

Hetmanska st., 20,

Melitopol, 72318

Ukraine.

Tel.: +38-098-558-37-55

E-mail: aikoshelev

4971@gmail.com

Oles Honchar Dipro

National University

Gagarin av., 72

Dnipro, 49000, Ukraine.

Tel.: +38-098-858-23-79.

E-mail:

kunah_olga@ukr.net

Koshelev, A. I., Pakhomov, O. Y., Kunakh, O. M., Koshelev, V. A., \& Fedushko, M. P. (2020). Temporal dynamic of the phylogenetic diversity of the bird community of agricultural lands in Ukrainian steppe drylands. Biosystems Diversity, 28(1), 34-40. doi:10.15421/012006

This study discussed the importance of the phylogenetic components in the structure of bird communities of anthropogenically transformed ecosystems. The investigation was conducted in the landscapes of the south and south-east of Ukraine in the nesting seasons 1988-2018. The bird community in the agricultural landscape was found to be presented by 10 species. The number of species was closely correlated with its phylogenetic analogue - Faith's index. Both indices were stationary over time, as they do not show a statistically significant time trend. The two axes were extracted as a result of the DPCOA procedure and the permutation test showed their statistical significance. The axis 1 was the most sensitive to the opposite dynamics of the abundance of Coturnix coturnix and Burhinus oedicnemus on the one hand and Alauda arvensis and Melanocorypha calandra on the other. The axis 2 is the most sensitive to the opposite dynamics of Corvus monedula and Melanocorypha calandra on the one hand and Coturnix coturnix and Motacilla flava on the other. Based on phylogenetic diversity, the years can be clustered with the extraction of four relatively homogeneous phylogenetic structures of bird communities. The indicator of the initial period of dynamics (1988-1992) was Burhinus oedicnemus. Sowing or mechanical weeding may be considered as a major factor of nest destruction of Burhinus oedicnemus. The decreasing of the abundance of the trophic recourses because of agricultural activity may have caused the monotonous negative trend over time of the Burhinus oedicnemus populations. The period 1993-2003 was a transitional one, for which there were no clear indicators, as a characteristic feature of this period was the processes of bird community restructuring. The period 2004-2013 was characterized by the loss of Burhinus oedicnemus from the community and a sharp increase in the abundance of Corvus monedula. These species are distinguished by their phylogenetic specificity and are located on the periphery relative to the phylogenetic core of the community. There was growing importance in the community of such species as Alauda arvensis, Anthus campestris, and Melanocorypha calandra between 2014 and 2018. Our results also confirm the assumption that phylogenetic overdispersion is an important requirement for the stability of the bird community in anthropogenically transformed landscapes.

Keywords: diversity; Faith's index; Rao's quadratic entropy; overdispersion; stability; global climate changes; agroecology.

\section{Introduction}

Bird assemblages have an amazing ecological diversity (Blinkova \& Shupova, 2017). The species assemblage of a community is the result of the interaction of evolutionary and ecological mechanisms (Ricklefs, 1987) and the latter being reflected in the niche-dependent (Tilman, 1982; Weiher \& Keddy, 1999; Zimaroeva et al., 2015), neutral (Bell, 2001; Hubbell, 2001) and historical (Ricklefs, 1987; Ricklefs \& Schluter, 1993) processes. Information about the phylogeny is suggested to be able to decide problems with estimation of the relative role of ecological niche, neutral and historical processes in formation of community structures (Cavender-Bares et al., 2009; Dranga et al., 2016; Gorlov et al., 2016; Chaplygina et al., 2018, 2019). Species richness is the commonest approach to quantifying community taxonomic diversity. Species abundances and species richness are useful metrics but are not able to give a full information on possible consequences of the land transformation and food production on ecosystem functioning or on evolution history (Dross et al., 2017). The effect of species richness on ecosystem productivity is strongly positive in low-productivity communities and strongly negative in high-productivity communities (Wang et al., 2019). The evaluation of evolutionary distances and relationships of species may be used to measure biodiversity (Faith, 2002; Zupan et al., 2014). The bird community functional alpha and beta diversities are found to be significantly correlated with taxonomic diversities (Si et al., 2016). Variability in the number of species may contribute to both phylogenet- ic clustering or overdispersion, depending on the habitat or scale studied (Sobral \& Cianciaruso, 2016; Sokolov \& Zhukov, 2016). Phylogenetic clustering is a situation where there is an excess of related species that coexist locally. Phylogenetic overdispersion is the situation where related species occur together less frequently than can be expected based on random assumptions (Hardy, 2008; Sokolov \& Zhukov, 2017).

Conservation of bird communities with high phylogenetic diversity is essential to maintain the diversity across the tree of life (Frishkoff et al., 2014; Thuiller et al., 2011). Phylogenetic diversity was also proposed as an important component for nature conservation (Vane-Wright et al., 1991; Winter et al., 2013). The phylogenetic diversity protection was suggested to be useful for protection of the functional diversity (Mazel et al., 2018). But phylogenetic diversity as a measure of the global biodiversity values cannot be reduced only to surrogate of the functional diversity for global conservation of phylogenetic diversity embraces more than just functional diversity (Owen et al., 2019). The level of a species' phylogenetic isolation is required to be assessed in conservation planning for choosing on which species to focus attention (Redding et al., 2014). The evolutionary distinctiveness is important because it represents uniquely divergent genomes (Faith, 2008; Jetz et al., 2014). The negative impact of urban environments on the evolutionary distinctiveness of birds was documented to be independent of eco-regions (Morelli et al., 2016). The multidimensionality of biodiversity needs to be considered to better understand the biodiversity-ecosystem multifunctionality relationship (Le Bagousse-Pinguet et al., 2019). Several 
benefits of maintaining the ecosystem's stability may be provided by conservation of phylogenetic diversity as a result of the decreasing probability of loss of the unique phenotypic and ecological traits $(\mathrm{Ca}-$ dotte et al., 2012). But there is alternative evidence according to which the conservation of evolutionarily distinct species is not more effective than the conservation of species richness as a way to maintain productive and stable communities under changing environmental conditions (Venail et al., 2015). Ecological niche conservatism suggests that phylogenetically related species tend to adapt to similar habitats because they have the equivalent biological properties (Lord et al., 1995). The phylogenetic and functional diversities were applied to quantify the impact of disturbances (Bässler et al., 2016), and to investigate overall drivers of biodiversity (Gerisch et al., 2012). There are different drivers of phylogenetic and functional diversity. Phylogenetic diversity is more sensitive to environmental factors but the functional diversity is more sensitive to habitat heterogeneity (Chun \& Lee, 2018). Land use intensification can reduce the functional diversity of animal communities beyond changes in species richness alone (Flynn et al., 2009; Zhukov et al., 2017). The mechanisms that influence the co-occurrence of species within the communities may be suggested to be similar along the ecological gradient due to the fact that the functional and phylogenetic evenness of the assemblages remained constant (Dehling et al., 2014).

Ecological diversity originates when climatic requirements, the feeding and breeding habitats and the food resources of the evolving lines of bird species repeatedly diverge during or between speciation events (Mayr, 1963). Species in anthropogenically transformed habitats are selectively eliminated from habitats (Si et al., 2017). Deforestation and forest fragmentation can cause species extinction, changing the phylogenetic community diversity (Arroyo-Rodriguez et al., 2012). Selective and random extinction may be discussed as alternative mechanisms to explain a biodiversity dynamic due to habitat loss and fragmentation (Terzopoulou et al., 2015; Si et al., 2016). Environmental filtering and competitive exclusion lead to selective extinction, creating community patterns that are different from random alternatives (MacArthur \& Levins, 1967; Purvis et al., 2000). The phylogenetic evenness of bird communities at regional scales can be an effect of historical biogeographic processes instead of niche-based processes (Gomez et al., 2010). The local abiotic conditions may eliminate the less fit species (Webb et al., 2002). Niche differences may only be explained by combinations of traits, corresponding to differentiation between species in multiple ecological dimensions (Kraft et al., 2015). It was suggested that communities on smaller and isolated fragments appear functionally and phylogenetically clustered. However, communities on the mainland should be overdispersed if competition is important or if there is high habitat heterogeneity (Si et al., 2017). The ecological resources are more limited in the smaller landscape patches and in these conditions the coexistence of species with similar niches may be restricted by an interspecific competition (Helmus et al., 2007).

The aim of the present work is to determine the importance of the phylogenetic components in the organization of bird communities of anthropogenically transformed ecosystems.

\section{Materials and methods}

The investigation was conducted in the landscapes of the south and south-east of Ukraine in the nesting seasons 1988-2018. Agricultural land was surveyed in the area around the Molochny Estuary $\left(46^{\circ} 33^{\prime} 00^{\prime \prime} \mathrm{N}\right.$, $35^{\circ} 24^{\prime} 17^{\prime \prime}$ E). The total survey area was 1092.4 ha. Two main methods of the ornithological surveys were applied to collect data: by transect and point (Andrushenko \& Zhukov, 2016; Koshelev, 2017). The width of the survey corridors with good visibility was $7-8 \mathrm{~km}$, during rain $-2-4 \mathrm{~km}$, in the fog - up to $500 \mathrm{~m}$ (in the specified boundaries it was maximum for larger species, and minimal - for small birds and individuals, which were in closed habitats with limited view). Point surveys were held during stops for scanning monotonous open areas. In all cases, the territory was examined using 12 binoculars and 60-X telescopes. Depending on the duration of the day and the quality of the illumination, counts were carried out throughout the daylight hours from 7:00-7:30 to 15:30-16:00. Counts were recorded in special cards, applied to the scale of 1:200,000 maps, and then transferred to the geographic information database created in the software ArcMap 10.0. Information about the phylogeny is applied to assess the phylogenic aspect of the diversity of bird communities. The Havrda \& Charvat index (Havrda \& Charvat, 1967) was used to measure the diversity within a community:

$$
H_{a}(p)=\left(1-\sum_{i=1}^{n} p_{i}^{a}\right) /(a-1),
$$

where $p=\left(p_{1}, \ldots, p_{i}, \ldots p_{n}\right), p_{i}$ is the relative abundance of the $i$-th category in a community of $n$ categories, and $a$ is a scaling constant $(a \geq 0)$ that weights the importance of rarity (Pavoine et al., 2009). When a tends to 1 , then $H_{a}$ tends to the Shannon (1948) index. When $a=2$, then $H_{a}$ is equal to the Simpson (1949) index (Pavoine et al., 2009). An index of phylogeny diversity (PD) adjusted for rarity $\left(I_{a}\right)$ was used (Pavoine et al., 2009):

$$
I_{i}=\sum_{K=1}^{N}\left(t_{K}-t_{K-1}\right) H_{a, K},
$$

where $H_{a}, K$ is the diversity index $H_{a}$ applied to the $K$-th period. With $a=$ $0, H_{0}$ is the richness and $I_{0}$ is Faith's (1992) PD index minus the height of the tree. When $a$ tends to 1, Ia is thus a generalization of the Shannon index $\left(H_{l}\right)$ to account for evolutionary history. With $a=2, H_{2}$ is the Simpson index and $I_{2}$ is Rao's quadratic entropy (QE) applied to phylogenetic distances between species (Pavoine et al., 2009).

Phylogenetic analysis by means of Double Principal Coordinate Analysis (DPCoA) (Pavoine et al., 2004) was conducted using library ade4 (Dray et al, 2007) in the environment R (R Core Team, 2019). Procedure of analysis and additional scripts are described in the work of Pavoine et al. (2009). For each random permutation of the phylogenetic tree as mentioned above we calculated eigenvalues of the DPCoA-axes and with function randtest from the library ade4 the Monte-Carlo test was performed. Statistical difference from the random alternative for each DPCoAaxis was assessed. This approach let us understand the degree in which phylogenetic information increases the quality of the ordination in comparison with the phylogenetic random alternative.

Statistical analysis was conducted in Statistica 10.0 (StatSoft Inc., USA). Randomization of the community matrix was done by means of the trial-swap algorithm maintaining species occurrence frequency and sample species richness (Miklos \& Podani, 2004). The permutation test was done by means of the randtest function from the ade4 packages (Dray \& Dufour, 2007).

\section{Results}

The bird community in agricultural landscape was found to be represented by 10 species during 1988-2018 (Fig. 1).

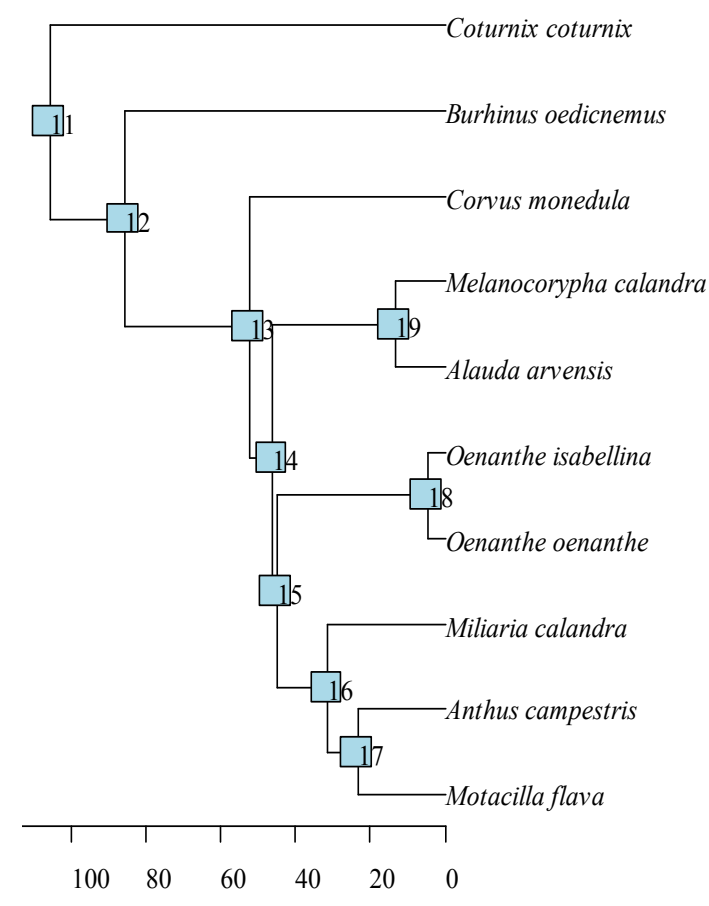

Fig. 1. Phylogenetic tree of the agrocenosis bird community: the scale is a time of divergence, million years 
The groups of the phylogenetically close species may be identified: Milaria calandra Linnaeus, 1758 and Alauda arvensis Linnaeus, 1758; Oenanthe isabellina (Temminck, 1829) and Oenanthe oenanthe (Linnaeus, 1758); Melanocorypha calandra (Linnaeus, 1766), Anthus campestris (Linnaeus, 1758) and Motacilla flava Linnaeus, 1758. Corvus monedula Linnaeus, 1758, Burhinus oedicnemus (Linnaeus, 1758) and Coturnix coturnix (Linnaeus, 1758) occupy an isolated position on the phylogenetic tree. The monotonous trend in population growth is typical for A. arvensis, A. campestris, Mel. calandra, Mil. calandra in the study period (Fig. 2). A monotonous decreasing trend in population dynamic is typical for $B$. oedicnemus, and $C$. coturnix. There was a maximum of the abundance of $C$. monedula, $M$. flava, and $O$. isabellina populations in the medium term of the study period. The some local max- ima were found for $O$. oenanthe. The bird communities of agrocenoses included 6-10 species annually in the current period of study (Fig. 3). The number of species was closely correlated with its phylogenetic analogue - index $I_{0}(\mathrm{r}=0.91, \mathrm{P}<0.001)$. Both indices were stationary over time, as they do not show a statistically significant time trend. The relationship between the Shannon index and the $I_{I}$ index was less than for the previous pair of indices $(r=0.77, \mathrm{P}<0.001)$. The Shannon index was stationary in time, and the $I_{l}$ index showed a trend of increase over time (the correlation with the order of years was $r=0.42, \mathrm{P}<0.02$ ). The Simpson index and $I_{2}$ index had the smallest correlation of all the pairs of indices reviewed $(r=0.65, \mathrm{P}<0.001)$. The Simpson index was stationary in time, and the $I_{2}$ index showed an upward trend (correlation with the order of years was $r=0.63, P<0.001$ ).

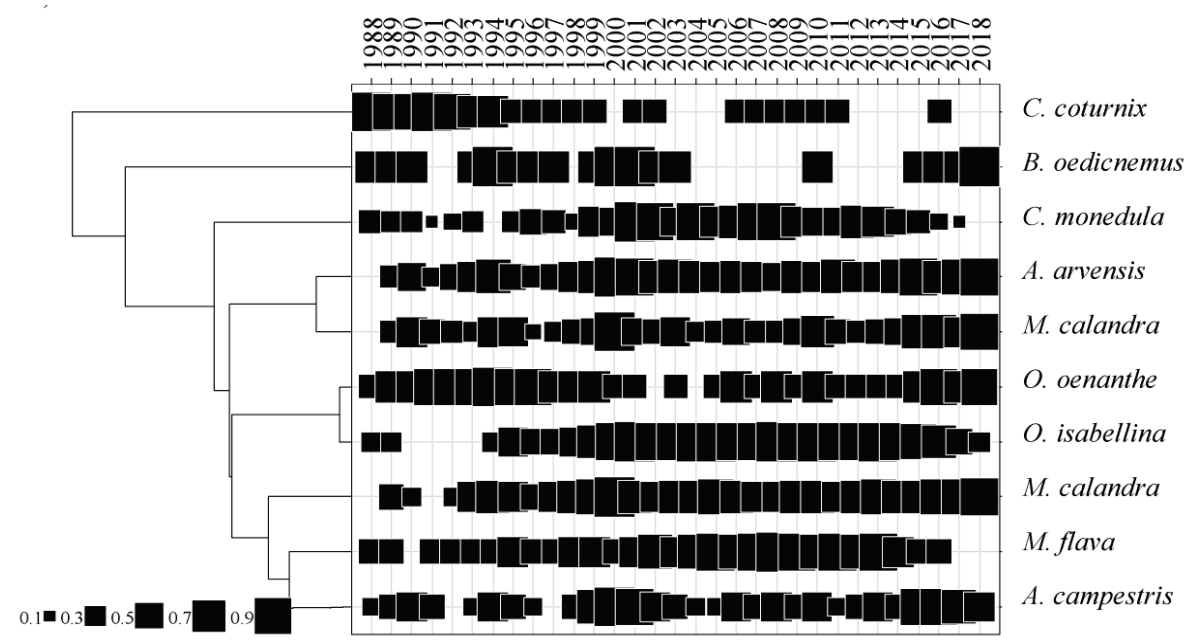

Fig. 2. Bird data set: the phylogenetic tree of the 10 bird species included in the analysis is provided; absolute abundances are measured by the number of birds detected per season (logarithm-transformed) and given by the size of black squares

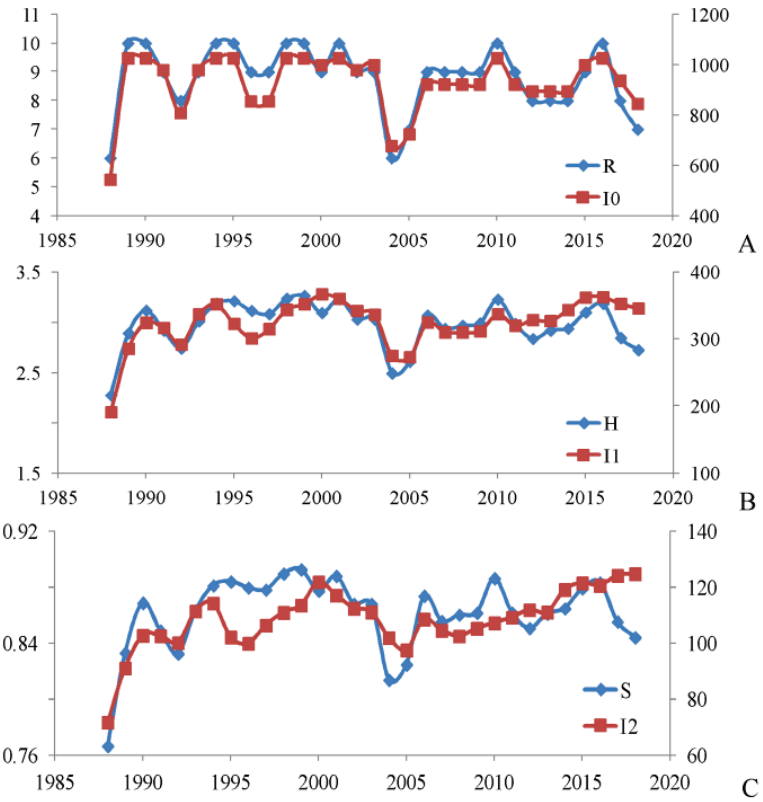

Fig. 3. The temporal dynamics of the diversity of bird communities of agrocenoses: horizontal axis is the order of years; $a$ - the left y-axis is the number of species, the right $y$-axis is the phylogenetic diversity $I_{0}$;

$b$-the left y-axis is the Shannon index, the right y-axis is the

phylogenetic diversity $I_{1} ; c$ - the left y-axis is the Simpson index, the right y-axis is the phylogenetic diversity $I_{2}$

The two axes were extracted as a result of the DPCOA procedure (Fig. 4). The permutation test showed their statistical significance. The eigenvalue of the axis 1 is 1.73 , which is different from the random alternative $1.29-0.05$ with significance level 0.05 . The eigenvalue of the axis 2 is 1.22 , which is different from the random alternative 0.86 .01 with signifi- cance level 0.012. The axis 1 was the most sensitive to the opposite dynamics of the abundance of $C$. coturnix and B. oedicnemus, on the one hand, and $A$. arvensis and M. calandra, on the other. The axis 2 is the most sensitive to the opposite dynamics of $C$. monedula and $M$. calandra on the one hand and C. coturnix and M. flava on the other.

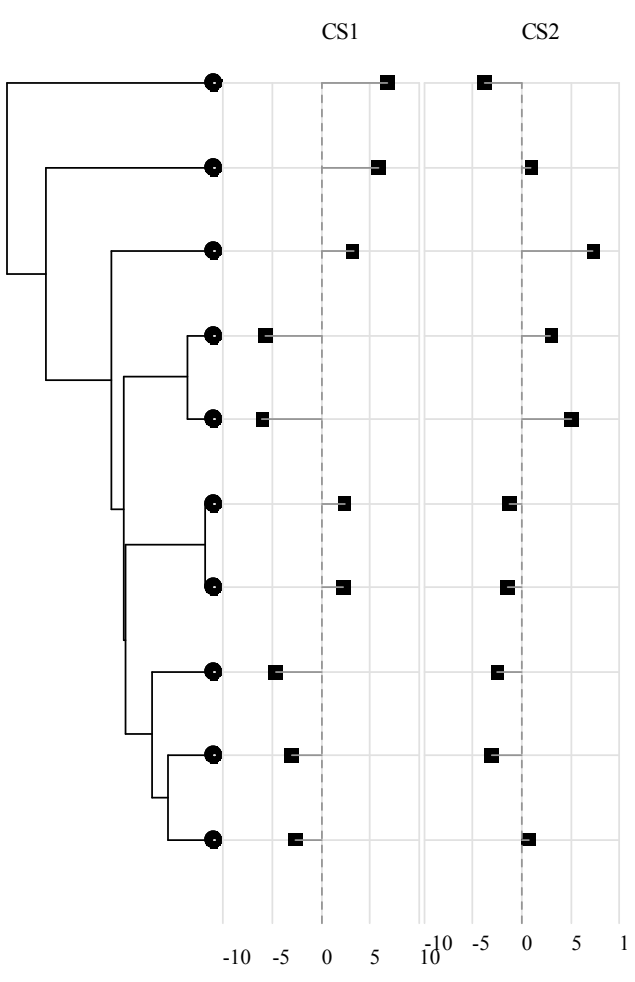

Fig. 4. Ordination of bird community by DPCoA based on phylogenetic structure 
The within-year variation component of phylogenetic community structure increased together with the order of diversity index $a(a=0,1,2)$ (Table 2). The between-year variation component of phylogenetic diversity varied between $3.1-9.2 \%$ depending on the order of diversity index, which indicates a rather high level of the temporal stability of community phylogenetic structure. The contribution of the evolutionary period to the partitioning of the I0, I1 and I2 indices between phylogenetic periods depends on the duration of the period (Fig. 5, a). The duration of the periods between successive events of the bird species formation represented in the community was 1.96-67.3 million years. By definition, the number of lines decreased from leaves to the root of a phylogenetic tree. Accordingly, the ecological contribution of the period decreased from leaves to roots. This pattern was most prevalent for the I0 index (Fig. 5, d), and to a slightly lesser extent for the I1 and I2 indices (Fig. 5, b, c). The most basal species were characterized by the least contribution to the difference of phylogenetic diversity between years.

\section{Table 2}

Overall value of $I a$ (total number for all phylogenetic periods, a = $0,1,2$ ) and its share within and between years $(\%$ indicate the proportion of total diversity attributable to the components of diversity within and between years)

\begin{tabular}{lrrrrrr}
\hline \multicolumn{1}{c}{ Diversity components } & \multicolumn{2}{c}{$I_{0}(\%$ from total $)$} & \multicolumn{2}{c}{$I_{1}$} & \multicolumn{2}{c}{$I_{2}$} \\
\hline Within-year diversity & 931.1 & $90.8 \%$ & 329.7 & $93.0 \%$ & 110.1 & $96.9 \%$ \\
\hline Between-year diversity & 94.7 & $9.2 \%$ & 24.8 & $7.0 \%$ & 3.5 & $3.1 \%$ \\
\hline Total diversity & 1025.8 & $100.0 \%$ & 354.4 & $100.0 \%$ & 113.6 & $100.0 \%$ \\
\hline
\end{tabular}

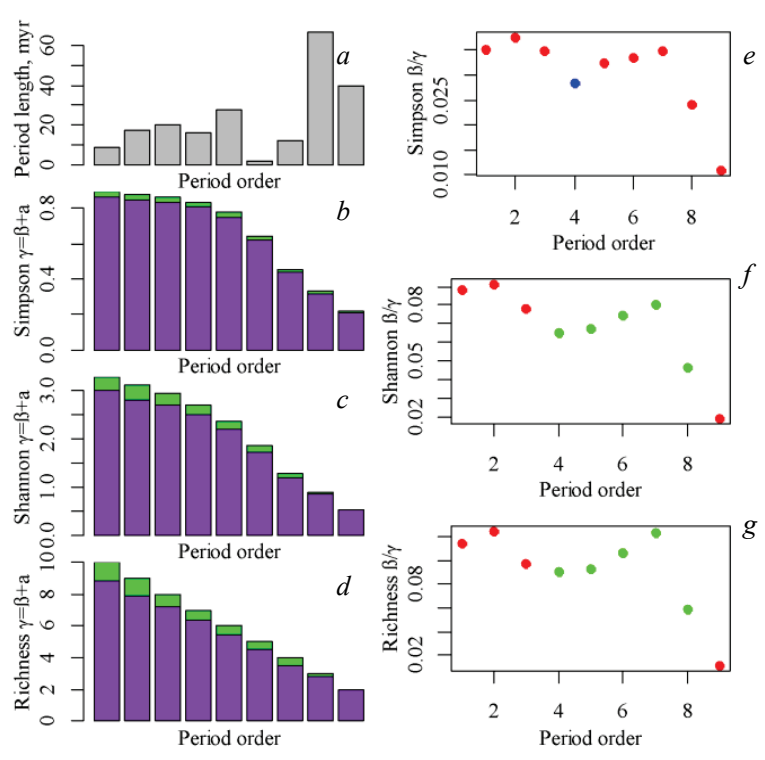

Fig. 5. Hierarchical partitioning of phylogenetic diversity across years and evolutionary periods: application to the bird data set. Periods are ordered from tips to root: (a) provides the length of the periods in million years; (b) gives the decomposition of Simpson diversity into $\alpha^{*}$ (purple bars), $\beta^{*}$ (green bars) components and across evolutionary periods (the height of the whole purple and green bar is $\left.\gamma^{*}\right) ;(c)$ and $(d)$ are equivalent bar plots for the Shannon $(c)$ and richness $(d)$ indices; in $(e)$, the difference between the years (measured $\beta^{*} \gamma^{*}$ with the Simpson index) is partitioned between the evolutionary periods; red circles highlight insignificant tests; green circles highlight significant tests revealing the overdispersion and blue circles highlight significant tests revealing the clusterisation; $(f)$ and $(g)$ are equivalent graphs for the Shannon $(f)$ and richness $(g)$ indices

The difference in phylogenetic diversity between years was estimated to increase using all indices between evolutionary period 2 (dichotomy 12 in Fig. 1) and 7 (dichotomy 17 in Fig. 1). The phylogenetic origin of the differences between the years (low value of the $\beta^{*} \gamma^{*}$ ratio, phylogenetic overdispersion) was statistically significant for periods of 4 to 8 (dichotomy 16 to 12 in Fig. 1) based on the $I_{0}$ and $I_{l}$ indices. This indicates that a greater number of the phylogenetic lines was formed during these periods than can be expected from a random alternative, and the $I_{l}$ index also indicates that the abundance of representatives of these lines in community is even. For the $I_{2}$ index, a statistically significant phylogenetic clustering was revealed for period 4 (the ratio $\beta^{*} \gamma^{*}$ was higher than can be expected based on a random alternative). This means that the abundance of the representatives of phylogenetic lines, which were below the specified significant period, varied considerably between years.

Based on phylogenetic diversity, the years can be clustered with the extraction of four relatively homogeneous phylogenetic structures of bird communities (Fig. 6).

As a rule, each cluster is contained in a series of years, allowing them to be considered as temporal periods. The homogeneous period was A (1988-1992). The cluster B mainly included the years 2004-2013, with the exception of 2010, which was a part of the cluster D. In turn, the cluster D corresponded to the period 1993-2003, with the exception of 2000, which was a part of the cluster $\mathrm{C}$. The cluster $\mathrm{C}$ embraced the period 2014-2018. It is obvious that the trajectory of the bird community development was not monotonous, which was due to some heterogeneity of the allocated periods.

The most sensitive to the phylogenetic structure was the period 4 and the corresponding monophyletic groups allowed us to interpret meaningfully the established periodization of the stages of development of the bird community. In the initial research period (cluster A) the community was associated with a relatively high frequency of occurrence of Burhinus oedicnemus . The transition to the next period (D) was due to the successive changes of the local maximum of abundance of the Oenanthe oenanthe (local maximum occurred in 1993-1994), Oenanthe isabellina (2001-2014), Motacilla flava (2008-2010). The next time period (B) was associated with a return of the community structural characteristics to initial state (similar to cluster A). The next period $\mathrm{C}$ was marked by an increase in the role of phylogenetically different species Alauda arvensis, Anthus campestris and the complex Melanocorypha calandra and Miliaria calandra.

\section{Discussion}

The study of community species composition is a key ecological problem (Pavoine et al., 2004). Human impact significantly reduces the diversity of biotic communities (Kunah \& Papka, 2016, a,b). Farmlands with high crop production can lead to a loss of avian phylogenetic diversity (Frishkoff et al., 2014; Morelli et al., 2017). It has been suggested that agriculture reduces the functional diversity of bird communities more than their taxonomic diversity (Dross et al., 2017). The effect of canopy density in temperate forests on taxonomic diversity of bird assemblages was generally bell-shaped, whereas the relationship was U-shaped for functional and phylogenetic diversity (Bae et al., 2018). This generalization was reflected in our results.

The modern agrolandscape in the south of Ukraine is a mosaic of various biotopes: arable fields, gardens, field-protective forest belts, irrigation canals and ponds, a network of roads, various buildings, inclusions of the remains of natural biotopes (steppes, meadows, solonchaks, rivers, etc.). According to our data, 56 bird species nest in agrolandscapes of Southern Ukraine. Only 10 species were found in the bird community in the agrocenoses which we monitored over 30 years of research, which, except for C. monedula, belong to the ecological group of campophiles. These species nest on the ground and collect food from the ground surface. C. monedula nests in hollow concrete poles among open woodless fields, but they also collect food from the ground, so they were included in this list. In this community 6-10 species were present annually. This raises the question of the nature of the mechanisms of formation and functioning of bird communities with low diversity level. Two alternative hypotheses can be offered. First, extreme environment regimes in the anthropogenically transformed landscapes offer relatively homogeneous conditions, which lead to a functional and phylogenetic homogenization of the communities. Another is that the intense competition between species in the extreme conditions should lead to phylogenetic overdispersion.

Information on phylogenesis is considered to be useful to decide some problems about the importance of the ecological niche, neutral and historical processes of the community, and some mechanisms of community structure formation (Cavender-Bares et al., 2009). Functional diversity explains resource-use patterns better than species diversity (Petchey \& Gaston, 2006). A lot of traits demonstrate a phylogenetic signal, suggest- 
ing that phylogenetic diversity can reveal the functional trait space of a community, and thus ecosystem functioning (Srivastava et al., 2012). The traditional diversity indices were found to be stationary, while the phylogenetic diversity indices indicated an increase in diversity over the study period. The reasons for this can be of different nature. During this period a rise in crop yields occurred (Kunah et al., 2018; Zymaroieva et al., 2019a, 2019b) that could affect the phylogenetic diversity of bird communities. The response of species richness and diversity to habitat complexity can be controlled by productivity, as species richness and diversity respond to productivity and increased resources in complex habitats (Hulbert, 2004). Also during this time period critical climate changes were observed, which have a mixed impact on the community of living organisms and in some cases can stimulate an increase in the diversity of some groups of animals or plants. Therefore, the trend of increasing of the phylogenetic diversity can be also linked to global climate change.
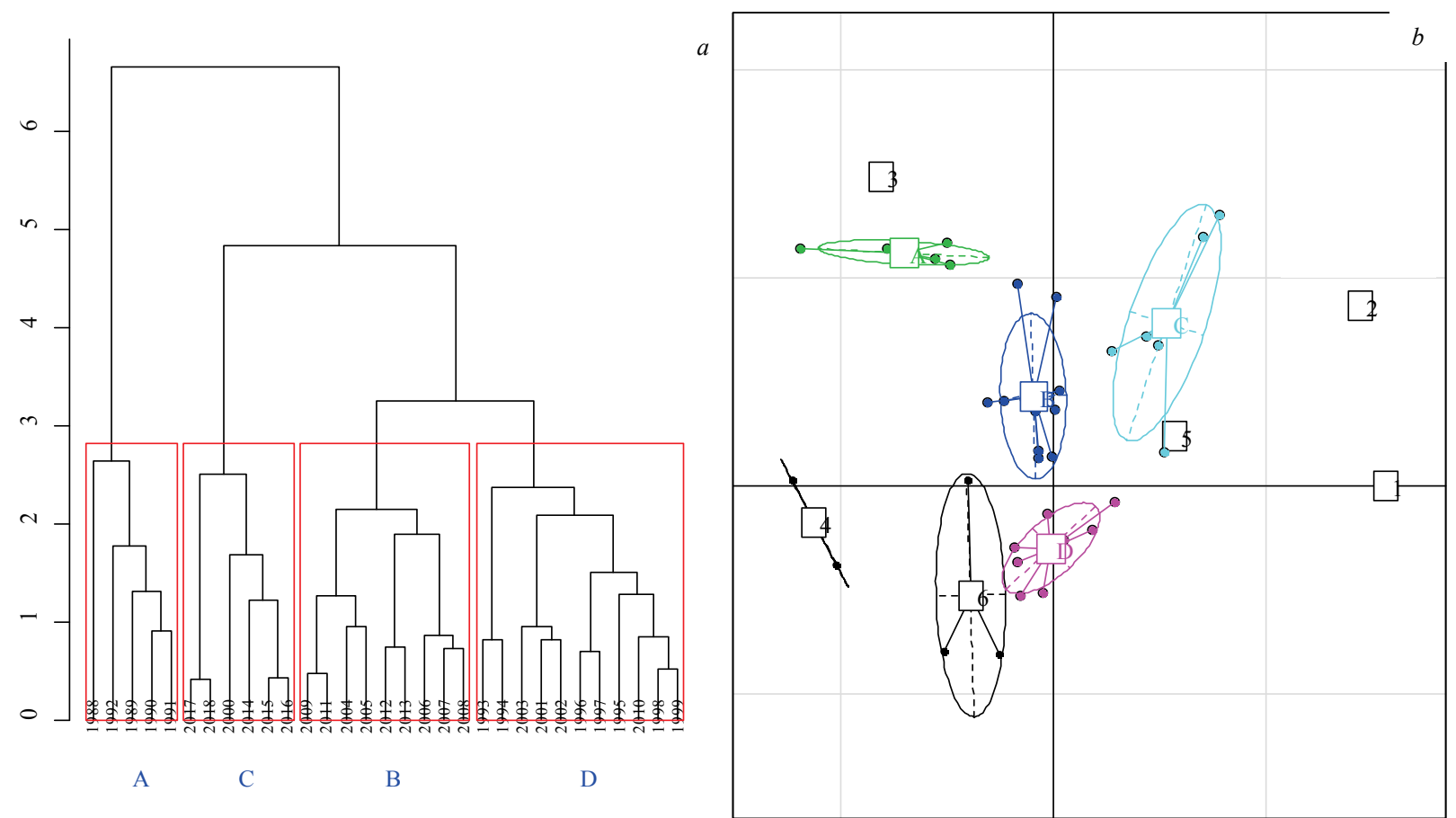

Fig. 6. Cluster analysis of the phylogenetic diversity of bird communities in different years based on the Rao metric $(a)$ and the results of a double analysis of the principal coordinates of the bird community with a phylogenetic matrix as a distance measure $(b)$ : the clusters of years on A (rectangles) are corresponded to clusters on B (ellipse); clusters of birds (monophyletic groups) are allocated for evolution period 4 (48 million years ago): 1 -Alauda arvensis; 2 - Anthus campestris; 3 -Burhinus oedicnemus; 4 -Coturnix coturnix, Corvus monedula; 5 -Melanocorypha calandra, Miliaria calandra; 6-Oenanthe oenanthe, Oenanthe isabellina, Motacilla flava

Phylogenetic diversity can reflect the diversity of unknown traits, which is why it was used as a proxy for functional diversity (Webb et al., 2002). Phylogenetic diversity is a key biodiversity attribute when it effectively encompasses unmeasured biological traits that are relevant for ecosystem functioning (Le Bagousse-Pinguet et al., 2019). The quantitative trend of phylogenetic diversity was associated with successive transformations of the bird community, which have a qualitative nature. These qualitative modifications are the basis for the typification of time series. The indicator of the initial period of dynamics (1988-1992) was Burhinus oedicnemus. This species is phylogenetically isolated. At present it is listed in the Red Book of Ukraine. Grazing, the disturbance factor, increase in number of feral dogs and crows are considered as the reasons for its population decrease. The demographic parameters of the Burhinus oedicnemus demonstated a total negative trend over time. Sowing or mechanical weeding may be considered as a major factor in the nest destruction of Burhinus oedicnemus (Gaget et al., 2019). The decline in bird populations is proportional to the agricultural intensity, and cereal yield alone is able to explain over $30 \%$ of the variation in population trends across Europe in the last quarter of the twentieth century (Donald et al., 2001). The decrease of diversity and abundance of insects as a food resource may be one of the possible mechanisms of the effect of agriculture on the habitat quality for birds (Johnson, 2007; Hallmann et al., 2014; Gilburn et al., 2015) and is due to the widespread application of pesticides (Geiger et al., 2010; Mineau \& Whiteside, 2013). The diet of the Burhinus oedicnemus is known to be based on mollusca, insecta, amphibia, and birds (Amat, 1986) or earthworms, soil-surface arthropods and mollusca (Green et al., 2000). The decrease in the abundance of these animals because of agricultural activity may have caused the monotonous negative trend over time for the Burhinus oedicnemus population. The period 1993-2003 was a transitional one, for which there were no clear indicators, as a characteristic feature of this period was the processes of bird community restructuring. These processes affect events related to the monophyletic group Oenanthe oenanthe, Oenanthe isabellina, Motacilla flava. The increase in abundance of Oenanthe isabellina, Motacilla flava and substitution of Oenanthe oenanthe by the phylogenetically close species Oenanthe isabellina should be noted. The peculiarity of the period was a sharp drop in agricultural production and subsequent growth after the stabilization of the socio-economic situation in the country (Zimaroeva et al., 2015, 2019a, 2019b). Obviously, the rapid dynamics of the ecological processes is the reason why there was no clear indicator of this period.

The period 2004-2013 was characterized by the loss of Burhinus oedicnemus from the community and a sharp increase in the abundance of Corvus monedula. These species are distinguished by their phylogenetic specificity and are located on the periphery relative to the phylogenetic core of the community. This indicates the importance of maintaining the phylogenetic overdispersion of the community as a condition for its sustainable functioning. A higher degree of functional and phylogenetic dispersion in fragmented areas may occur due to the competitive exclusion of closely related species with similar features or resource requirements (Sobral \& Cianciaruso, 2016). The phylogenetic overdispersion can be a consequence of a) exclusion due to competition between two closely related species with similar ecological requirements; b) mortality that is determined by the density of closely related species; c) ecological species formation that is affected by habitat differentiation between related species (Cavender-Bares et al., 2004, 2006; Gilbert \& Webb, 2007). The rate of evolutionary changes is much lower than the rate of anthropogenic transformation of ecosystems, so the actual causes of phylogenetic overdispersion should be considered as variants $a$ and $b$. 
There was growing importance in the community of such species as Alauda arvensis, Anthus campestris, and Melanocorypha calandra between 2014 and 2018. The species Alauda arvensis and Melanocorypha calandra are phylogenetically close, while Anthus campestris is at a significant phylogenetic distance from them. Such a result also confirms the assumption that phylogenetic overdispersion is an important requirement for the stability of the bird community in anthropogenically transformed landscapes.

\section{Conclusion}

After long term research the bird community in agricultural areas was shown to be represented by a very small number of species. The species composition indicates that this community is a derivative of steppe zonal ecosystems. The low diversity of the community leaves an opportunity to maintain its sustainability and to respond to the intensity of dynamics of human pressure and the changing global climate situation. The phylogenetic aspect is an important source of information for assessing the diversity of the bird community of anthropogenically transformed biotopes. The phylogenetic diversity of the bird community demonstrates the presence of trends in both clusterization and overdispersion. The phylogenetic clusterization is found for the dominant bird species, which indicates the ecological homogeneity of the community component, which plays a key role in its functioning. The phylogenetic overdispersion is subject to indicators of diversity that are more sensitive to the number of species than to their abundance. It is this aspect of diversity that reflects a community's ability to adapt to changing environmental conditions. This result underlines the importance of efforts to protect endangered bird species in anthropogenically transformed areas.

\section{References}

Amat, J. A. (1986). Information on the diet of the stone curlew Burhinus oedicnemusin Doñana, Southern Spain. Bird Study, 33, 71-73.

Andrushenko, A. Y., \& Zhukov, A. V. (2016). Scale-dependent effects in structure of the wintering ecological niche of the mute swan during wintering in the gulf of Sivash. Biological Bulletin of Bogdan Chmelnitskiy Melitopol State Pedagogical University, 6(3), 234-247.

Arroyo-Rodriguez, V., Cavender-Bares, J., Escobar, F., Melo, F., Tabarelli, M. \& Santos, B. (2012). Maintenance of tree phylogenetic diversity in a highly fragmented rain forest. Journal of Ecology, 100, 702-711.

Bae, S., Müller, J., Lee, D., Vierling, K. T., Vogeler, J. C., Vierling, L. A., Hudak, A T., Latifi, \& Thom, H. S. (2018). Taxonomic, functional, and phylogenetic diversity of bird assemblages are oppositely associated to productivity and heterogeneity in temperate forests. Remote Sensing of Environment, 215, 145-156.

Bässler, C., Müller, J., Cadotte, M., Heibl, C., Bradtka, J., Thom, S., \& Halbwachs, H. (2016). Functional response of lignicolous fungal guilds to bark beetle deforestation. Ecological Indicators, 65, 149-160.

Bell, G. (2001). Neutral macroecology. Science, 293, 2413-2418.

Blinkova, O., \& Shupova, T. (2017). Bird communities and vegetation composition in the urban forest eco-system: Correlations and comparisons of diversity indices. Ekológia (Bratislava), 36(4), 366-387.

Cadotte, M. W., Dinnage, R., \& Tilman, D. (2012). Phylogenetic diversity promotes ecosystem stability. Ecology, 93, 223-233.

Cavender-Bares, J., Ackerly, D., Baum, D., \& Bazzaz, F. (2004). Phylogenetic overdispersion in Floridian oak communities. American Naturalist, 163, 823-843.

Cavender-Bares, J., Keen, A., \& Miles, B. (2006). Phylogenetic structure of Floridian plant communities depends on taxonomic and spatial scale. Ecology, 87, S109-S122.

Cavender-Bares, J., Kozak, K., Fine, P., \& Kembel, S. (2009). The merging of community ecology and phylogenetic biology. Ecological Letters, 12(7), 693-715.

Chaplygina, A. B., Pakhomov, O. Y., \& Brygadyrenko, V. V. (2019). Trophic links of the song thrush (Turdus philomelos) in transformed forest ecosystems of North-Eastern Ukraine. Biosystems Diversity, 27(1), 51-55.

Chaplygina, A. B., Savynska, N. O., \& Brygadyrenko, V. V. (2018). Trophic lincs of the spotted flycatcher, Muscicapa striata, in transformed forest ecosystems of North-Eastern Ukraine. Baltic Forestry, 24(2), 304-312.

Chun, J., \& Lee, C. (2018). Partitioning the regional and local drivers of phylogenetic and functional diversity along temperate elevational gradients on an East Asian peninsula. Scientific Reports, 8, 2853.

Dehling, D., Fritz, S., Töpfer, T., Päckert, M., Estler, P., Böhning-Gaese, K., \& Schleuning, M. (2014). Functional and phylogenetic diversity and assem- blage structure of frugivorous birds along an elevational gradient in the tropical Andes. Ecography, 37, 1047-1055.

Donald, P. F., Green, R. E., \& Heath, M. F. (2001). Agricultural intensification and the collapse of Europe's farmland bird populations. Proceedings of the Royal Society B, Biological Sciences, 155(1462), 39-43.

Dranga, A. O., Gorlov, P. I., Matsyura, A. V., \& Budgey, R. (2016). Breeding biology of rook (Corvus frugilegus) in the human transformed steppe ecosystems (the case of Botievo Wind Farm). Biological Bulletin of Bogdan Chmelnitskiy Melitopol State Pedagogical University, 6(1), 41-62.

Dray, S., \& Dufour, A. (2007). The ade4 package: Implementing the duality diagram for ecologists. Journal of Statistical Software, 22(4), 1-20.

Dross, C., Jiguet, F., \& Tichit, M. (2017). Concave trade-off curves between crop production and taxonomic, functional and phylogenetic diversity of birds. Ecological Indicators, 79, 83-90.

Faith, D. P. (2002). Quantifying biodiversity: A phylogenetic perspective. Conservation Biology, 16(1), 248-252.

Faith, D. P. (2008). Threatened species and the potential loss of phylogenetic diversity: Conservation scenarios based on estimated extinction probabilities and phylogenetic risk analysis. Conservation Biology, 22(6), 1461-1470.

Flynn, D., Gogol-Prokurat, M., Nogeire, T., Molinari, N., Richers, B., Lin, B., Simpson, N., Mayfield, M., \& DeClerck, F. (2009). Loss of functional diversity under land use intensification across multiple taxa. Ecology Letters, 12, 22-33.

Frishkoff, L., Karp, D., M'Gonigle, L., Mendenhall, C., Zook, J., Kremen, C., Hadly, E., \& Daily, G. (2014). Loss of avian phylogenetic diversity in neotropical agricultural systems. Science, 345(6202), 1343-1346.

Gaget, E., Fay, R., Augiron, S., Villers, A., \& Bretagnolle, V. (2019). Long-term decline despite conservation efforts questions Eurasian Stone-curlew population viability in intensive farmlands. Ibis, 161, 359-371.

Geiger, F., Bengtsson, J., Berendse, F., Weisser, W., Emmerson, M., Morales, M. Ceryngier, P., Liira, J., Tscharntke, T., Winqvist, C., Eggers, S., Bommarco, R., Pärt, T. Bretagnolle, V., Plantagenest, M., Clement, L., Dennis, C., Palmer, C., Oñate, J., Guerrero, I., Hawro, V., Aavik, T., Thies, C., Flohre, A., Hänke, S., Fischer, C., Goedhart, P., \& Inchausti, P. (2010). Persistent negative effects of pesticides on biodiversity and biological control potential on European farmland. Basic and Applied Ecology, 11(2), 97-105.

Gerisch, M., Agostinelli, V., Henle, K., \& Dziock, F. (2012). More species, but all do the same: Contrasting effects offlood disturbance on ground beetle functional and species diversity. Oikos, 121, 508-515.

Gilbert, G. S., \& Webb, C. O. (2007). Phylogenetic signal in plant pathogen - host range. Proceedings of the National Academy of Sciences, United States of America, 104, 4979-4983.

Gilburn, A. S., Bunnefeld, N., Wilson, J. M., Botham, M. S., Brereton, T. M., Fox, R., \& Goulson, D. (2015). Are neocotinoid insecticides driving declines of widespread butterflies? PeerJ, 3, e1402.

Gomez, J. P., Bravo, G. A., Brumfield, R. T., Tello, J. G. \& Cadena, C. D. (2010). A phylogenetic approach to disentangling the role of competition and habitat filtering in community assembly of Neotropical forest birds. Journal of Animal Ecology, 79, 1181-1192.

Gorlov, P. I., Siokhin, V. D., \& Matsyura, A. V. (2016). Assessment of potential threats of wind farms for migratory birds in the south of Ukraine. Biological Bulletin of Bogdan Chmelnitskiy Melitopol State Pedagogical University, 6(3), 175-186

Green, R. E., Tyler, G. A., \& Bowden, C. G. (2000). Habitat selection, ranging behavior and diet of the stone curlew (Burhinus oedicnemus) in Southern England. Journal of Zoology, 250(2), 161-183.

Hallmann, C. A., Foppen, R. P., van Turnhout, C. A., de Kroon, H. P., \& Jongejans, E. R. (2014). Declines in insectivorous birds are associated with high neonicotinoid concentrations. Nature, 511, 341-343.

Hardy, O. J. (2008). Testing the spatial phylogenetic structure of local communities: Statistical performances of different null models and test statistics on a locally neutral community. Journal of Ecology, 96, 914-926.

Havrda, M., \& Charvat, F. (1967). Quantification method of classification processes: Concept of structurala - entropy. Kybernetik, 3, 30-35.

Helmus, M., Savage, K., Diebel, M., Maxted, J., \& Ives, A. (2007). Separating the determinants of phylogenetic community structure. Ecology Letters, 10, 917-925.

Hubbell, S. P. (2001). The unified neutral theory of biodiversity and biogeography. Princeton University Press, Princeton, New Jersey.

Hulbert, A. H. (2004). Species-energy relationships and habitat complexity in bird communities. Ecology Letters, 7, 714-720.

Jetz, W., Thomas, G., Joy, J. B., Redding, D., Hartmann, K., \& Mooers, A (2014). Global distribution and conservation of evolutionary distinctness in birds. Conservation Biology, 24(9), 919-930.

Johnson, M. D. (2007). Measuring habitat quality: A review. Condor, 109, 489-504.

Koshelev, V. A. (2017). Ornithocomplexes reeds: The structure, dynamics, problems of protection. Biology and Valeology, 19, 16-27. 
Kraft, N. J., Godoy, O. Y., \& Levine, J. M. (2015). Plant functional traits and the multidimensional nature of species coexistence. Proceedings of the National Academy of Sciences United States of America, 112, 797-802.

Kunah, O. M., \& Papka, O. S. (2016a). Geomorphological ecogeographical variables definig features of ecological niche of common milkweed (Asclepias syriaca L.). Biological Bulletin of Bogdan Chmelnitskiy Melitopol State Pedagogical University, 1, 243-275.

Kunah, O. M., \& Papka, O. S. (2016b). Ecogeographical determinants of the ecological niche of the common milkweed (Asclepias syriaca) on the basis of indices of remote sensing of land images. Visnyk of Dnipropetrovsk University, Biology, Ecology, 24(1), 78-86.

Kunah, O. M., Pakhomov, O. Y., Zymaroieva, A. A., Demchuk, N. I., Skupskyi, R. M., Bezuhla, L. S., \& Vladyka, Y. P. (2018). Agroeconomic and agroecological aspects of spatial variation of rye (Secale cereale) yields within Polesia and the Forest-Steppe zone of Ukraine: The usage of geographically weighted principal components analysis. Biosystems Diversity, 26(4), 276-285.

Lord, J., Westoby, M., \& Leishman, M. (1995). Seed size and phylogeny in 6 temperate floras - constraints, niche conservatism, and adaptation. American Naturalist, 146, 349-364.

MacArthur, R., \& Levins, R. (1967). The limiting similarity, convergence, and divergence of coexisting species. American Naturalist, 101, 377-385.

Mayr, E. (1963). Animal species and evolution. Belknap, Cambridge.

Mazel, F., Pennell, M., Cadotte, M., Diaz, S., Riva, G., Grenyer, R., Leprieur, F., Mooers, A., Mouillot, D., Tucker, C., \& Pearse, W. (2018). Prioritizing phylogenetic diversity captures functional diversity unreliably. Nature Communication, 9,2888

Miklos, I., \& Podani, J. (2004). Randomization of presence-absence matrices: Comments and new algorithms. Ecology, 85(1), 86-92.

Mineau, P., \& Whiteside, M. (2013). Pesticide acute toxicity is a better correlate of U.S. grassland bird declines than agricultural intensification. PLoS One, 8(2), e57457.

Morelli, F., Benedetti, Y., Ibáñez-álamo, J., Jokimäki, J., Mänd, R., Tryjanowski, P., \& Møller, A. (2016). Evidence of evolutionary homogenization of bird communities in urban environments across Europe. Global Ecology and Biogeography, 25(11), 1284-1293.

Morelli, F., Jiguet, F., Sabatier, R., Dross, C., Princé, K., Tryjanowski, P., \& Tichit, M. (2017). Spatial covariance between ecosystem services and biodiversity pattern at a national scale (France). Ecological Indicators, 82, 574-586.

Owen, N., Gumbs, R., Gray, C., \& Faith, D. (2019). Global conservation of phylogenetic diversity captures more than just functional diversity. Nature Communication, 10, 859 .

Pavoine, S., Dufour, A.-B., \& Chessel, D. (2004). From dissimilarities among species to dissimilarities among communities: A double principal coordinate analysis. Journal of Theoretical Biology, 228, 523-537.

Pavoine, S., Love, M., \& Bonsall, M. (2009). Hierarchical partitioning of evolutionary and ecological patterns in the organization of phylogeneticallystructured species assemblages: Application to rockfish (genus: Sebastes) in the Southern California Bight. Ecology Letters, 12, 898-908.

Petchey, O. L., \& Gaston, K. J. (2006). Functional diversity: Back to basics and looking forward. Ecology Letters, 9(6), 741-758.

Purvis, A., Agapow, P.-M., Gittleman, J., \& Mace, G. M. (2000). Nonrandom extinction and the loss of evolutionary history. Science, 288, 328-330.

R Core Team (2019). R: A language and environment for statistical computing. R Foundation for Statistical Computing, Vienna.

Redding, D., Mazel, F., \& Mooers, A. (2014). Measuring evolutionary isolation for conservation. PLoS One, 9(12), e113490.

Ricklefs, R. E. (1987). Community diversity: Relative roles of local and regional processes. Science, $235,167-171$.

Ricklefs, R., \& Schluter, D. (1993). Species diversity: Regional and historical influences. In: Ricklefs, R. E., \& Schluter, D. (Eds.). Species diversity in ecological communities. University of Chicago Press, Chicago. Pp. 350-363.

Shannon, C. (1948). A mathematical theory of communication. Bell System Technology Journal, 27, 379-423.
Si, X., Baselga, A., Leprieur, F., Song, X., \& Ding, P. (2016). Selective extinction drives taxonomic and functional alpha and beta diversities in island bird assemblages. Journal of Animal Ecology, 85, 409-418.

Si, X., Cadotte, M., Zeng, D., Baselga, A., Zhao, Y., Li, J., Wu, Y., Wang, S., \& Ding, P. (2017). Functional and phylogenetic structure of island bird communities. Journal of Animal Ecology, 86, 532-542.

Sobral, F. L., \& Cianciaruso, M. V. (2016). Functional and phylogenetic structure of forest and savanna bird assemblages across spatial scales. Ecography, 39, 533-541.

Sokolov, S. G., \& Zhukov, A. V. (2016). The diversity of parasites in the chinese sleeper Perccottus glenii Dybowski, 1877 (Actinopterygii: Perciformes) under the conditions of large-scale range expansion. Biology Bulletin, 43(4), $374-383$.

Sokolov, S. G., \& Zhukov, A. V. (2017). Functional diversity of a parasite assemblages of the chinese sleeper Perccottus glenii Dybowski, 1877 (Actinopterygii: Odontobutidae) and habitat structure of the host. Biology Bulletin, 44(3), 331-336.

Srivastava, D. S., Cadotte, M. W., MacDonald, A. A., Marushia, R. G., \& Mirotchnick, N. P. (2012). Phylogenetic diversity and the functioning of ecosystems. Ecology Letters, 15, 637-648.

Terzopoulou, S., Rigal, F., Whittaker, R., Borges, P., \& Triantis, K. (2015). Drivers of extinction: The case of Azorean beetles. Biology Letters, 11, 20150273.

Thuiller, W., Lavergne, S., Roquet, C., Boulangeat, I., Lafourcade, B., \& Araújo, M. (2011). Consequences of climate change on the tree of life in Europe. Nature, 470, 531-534.

Tilman, D. (1982). Resource competition and community structure. Princeton University Press, Princeton.

Vane-Wright, R. I., Humphries, C. J., \& Williams, P. H. (1991). What to protect? Systematics and the agony of choice. Biological Conservation, 55(3), 235-254.

Venail, P., Gross, K., Oakley, T., Narwani, A., Allan, E., Flombaum, P., Isbell, F., Joshi, J., Reich, P., Tilman, D., van, Ruijven, J., \& Cardinale, B. (2015). Species richness, but not phylogenetic diversity, influences community biomass production and temporal stability in a re-examination of 16 grassland biodiversity studies. Functional Ecology, 29, 615-626.

Wang, Y., Cadotte, M., Chen, Y., Fraser, L., Zhang, Y., Huang, F., Luo, S., Shi, N., \& Loreau, M. (2019). Global evidence of positive biodiversity effects on spatial ecosystem stability in natural grasslands. Nature Communication, 10, 3207.

Webb, C. O., Ackerly, D. D., McPeek, M. A., \& Donoghue, M. J. (2002). Phylogenies and community ecology. Annual Review of Ecology, Evolution and Systematics, 33, 475-505.

Weiher, E., \& Keddy, P. (1999). Ecological assembly rules: Perspectives, advances, retreats. Cambridge University Press, Cambridge.

Winter, M., Devictor, V., \& Schweiger, O. (2013). Phylogenetic diversity and nature conservation: Where are we? Trends in Ecology and Evolution, 28(4), 199-204.

Zhukov, A. V., Sirovatko, V. O., \& Ponomarenko, N. O. (2017). Spatial dynamic of the agriculture fields towards their shape and size. Ukrainian Journal of Ecology, 7(3), 14-31.

Zimaroeva, A., Zhukov, A., \& Ponomarenko, A. (2015). Determining spatial parameters of the ecological niche of Parus major (Passeriformes, Paridae) on the base of remote sensing data. Vestnik Zoologii, 49(2), 451-456.

Zupan, L., Cabeza, M., Maiorano, L., Roquet, C., Devictor, V., Lavergne, S., Mouillot, D., Mouquet, N., Renaud, J., \& Thuiller, W. (2014). Spatial mismatch of phylogenetic diversity across three vertebrate groups and protected areas in Europe. Diversity and Distribution, 20(6), 674-685.

Zymaroieva, A., Zhukov, O., Fedonyuk, T., \& Pinkin, A. (2019b). Application of geographically weighted principal components analysis based on soybean yield spatial variation for agro-ecological zoning of the territory. Agronomy Research, 17(6), 2460-2473

Zymaroieva, A., Zhukov, O., Romanchuck, L., \& Pinkin, A. (2019a). Spatiotemporal dynamics of cereals grains and grain legumes yield in Ukraine. Bulgarian Journal of Agricultural Science, 25(6), 1107-1113. 